\title{
Prevalência de infecções oportunistas em pacientes HIV positivos atendidos no Centro de Testagem e Aconselhamento (CTA) em município do Pará, em 2015 e 2016
}

\author{
Prevalence of opportunistic infections in HIV positive patients served at the testing and \\ counseling center (CTA) in municipality of Pará, in 2015 and 2016
}

Prevalencia de infecciones oportunistas en pacientes VIH positivos servidos en el centro pruebas y asesoramiento (CTA) em el município de Pará, em 2015 y 2016

Luiz Lima Chaves ${ }^{1}$, Camila dos Santos Freitas ${ }^{1}$, Gabrielly da Silva Costa ${ }^{1}$, Maria Mônica Machado de Aguiar Lima ${ }^{1}$, Marystela Batista Martins ${ }^{3}$, Israela Cristine Pereira Marinho², Yanka Rafaela da Costa Neto Vieira ${ }^{2 *}$, Ana Karina Corôa Vasconcelos ${ }^{2}$, Lucas da Costa Kalif ${ }^{2}$, Ana Luiza de Sousa Barbosa².

\section{RESUMO}

Objetivo: Determinar o perfil e prevalência de infecções oportunistas em pacientes soropositivos para o vírus da Imunodeficiência Humana (HIV) atendidos no Centro de Testagem de Aconselhamento (CTA) (Centro de Testagem e Aconselhamento) de uma cidade do estado do Pará. Métodos: Estudo descritivo retrospectivo, observacional, transversal com dados coletados a partir dos prontuários dos usuários do CTA, entre janeiro de 2015 e dezembro de 2016. Foram seguidas as determinações da Resolução 566/12 do CNS. Resultados: No período pesquisado, cerca de 467 pacientes faziam acompanhamento no CTA em questão. Dentre estes, $66 \%$ eram homens e $34 \%$ mulheres, com idade de detecção média entre 21 e 30 anos, possuindo, em maioria, instrução somente até o Ensino Fundamental. Em relação às infecções oportunistas, a tuberculose foi a infecção mais prevalente, seguida pela neurotoxoplasmose e candidíase oral. Conclusão: Por meio desta pesquisa, foi possível encontrar o perfil epidemiológico dos pacientes com HIV atendidos no local sendo uma pesquisa que servirá para o desenvolvimento de busca ativa por meio dos órgãos de saúde e educação em saúde direcionada.

Palavras-chave: HIV, Infecções oportunistas, Tuberculose, Toxoplasmose cerebral, Candidíase.

\section{ABSTRACT}

Objective: To determine the prevalence of opportunistic infections in seropositive people for the Human Immunodeficiency Virus (HIV) treated at the Counseling Test Center (CTA) of a city in the Pará, between January 2015 and December 2016. Methods: Retrospective, observational, cross-sectional study with data collected from the medical records of CTA users. The determinations of Resolution 566/12 of the CNS were followed. Results: In the period surveyed, about 467 patients were being followed up at the CTA in question. Among these, $66 \%$ were men and 34\% women, with an average age of detection between 21 and 30 years, most of whom had instruction only until elementary school. Regarding opportunistic infections, tuberculosis was the most prevalent infection, followed by neurotoxoplasmosis and oral candidiasis. Conclusion: Through this research, it was possible to find the epidemiological profile of HIV patients treated at the site, being a research that will serve to develop an active search through the health agencies and directed health education.

Key words: HIV, Opportunistic infections, Tuberculosis, Cerebral toxoplasmosis, Candidiasis.

1 Universidade do Estado do Pará (UEPA), Santarém - PA. *E-mail: rafaela_yanka@hotmail.com ${ }^{2}$ Centro Universitário Metropolitano da Amazônia (UNIFAMAZ), Belém - PA.

3Universidade Nilton Lins, Manaus - AM.

SUBMETIDO EM: 4/2020

PUBLICADO EM: 7/2020 


\section{RESUMEN}

Objetivo: Determinar la prevalencia de infecciones oportunistas en personas seropositivas para el Virus de Inmunodeficiencia Humana (VIH) tratados en la Centro de Pruebas e Asesoriamento (CTA) de una ciudad, en el estado de Pará, entre enero de 2015 y diciembre de 2016. Métodos: Estudio retrospectivo, observacional, transversal con datos recogido de los registros médicos de usuarios de CTA. Se siguieron las determinaciones de la Resolución 566/12 del CNS. Resultados: En el período encuestado, se hizo un seguimiento de aproximadamente 467 pacientes en la CTA en cuestión. Entre estos, el 66\% eran hombres y el $34 \%$ mujeres, con una edad promedio de detección entre 21 y 30 años, y la mayoría de ellos tenían una educación solo hasta la escuela primaria. En cuanto a las infecciones oportunistas, la tuberculosis fue la infección más prevalentes, seguida de la neurotoxoplasmosis y la candidiasis oral. Conclusión: Através de esta investigación, fue posible encontrar el perfil epidemiológico de los pacientes con VIH tratados en el sitio, siendo una investigación que servirá para desarrollar una búsqueda activa a través de las agencias de salud y la educación sanitaria dirigida.

Palabras clave: VIH, Infecciones oportunistas, Tuberculosis, Toxoplasmosis cerebral, Candidiasis.

\section{INTRODUÇÃO}

Passados mais de 30 anos da descoberta do vírus da imunodeficiência humana (HIV) e a despeito da tendência a estabilização da epidemia no Brasil, ainda se considera a síndrome da imunodeficiência adquirida (AIDS) como uma pandemia. Estima-se que em 2011 existiam no mundo 34 milhões de pessoas entre homens, mulheres e crianças infectadas pelo HIV.

Somente no ano de 2011, 2,5 milhões de pessoas foram infectados pelo HIV e 1,7 milhões morreram em decorrência da AIDS, a maioria devido ao acesso inadequado a serviços de tratamento e atenção (MAHY M, et al., 2009; MAGNO ES, et al., 2017).

É importante analisar que o contágio do HIV é silencioso por meio de relação sexual sem camisinha ou contato com secreções de uma pessoa infectada, transfusão sanguínea de uma pessoa com o vírus e transmissão vertical (durante a gestação) e, por ser uma doença que em seu início aparecem sintomas inespecíficos tais como febre, dores no corpo e enjoo, as pessoas não se importam. Contudo com a replicação viral, ocorre o agravamento desses sintomas e o aparecimento de doenças que podem levar a óbito tais como Tuberculose pela imunidade estar debilitada (MAGNO ES, et al., 2017).

O diagnóstico da AIDS é associado à presença de outras infecções consideradas oportunistas que raramente infectaria um indivíduo com imunidade competente, dessa forma é feito os testes para a pesquisa do HIV (LIMA LB, 2011).

As doenças oportunistas estão fortemente associadas à infecção pelo HIV. A principal característica patológica do vírus da imunodeficiência humana é a diminuição progressiva da imunidade celular e o consequente aparecimento de infecções oportunistas e neoplasias malignas.

A infecção compromete o sistema imune de maneira sistêmica, tornando-a suscetível a diversas alterações, tais como: candidíase, herpes vírus, malária, pneumonia, tuberculose, leucoplasia pilosa, sarcoma de Kaposi, linfoma não-Hodgkin, gengivite ulcerativa necrotizante aguda e periodontite.

A grande evolução ocorrida nos últimos anos no tratamento medicamentoso do HIV/AIDS, principalmente em relação à terapia antirretroviral de alta potência, tem garantido um aumento significativo na sobrevida dos indivíduos afetados pelo HIV/AIDS (BRASIL, 2016; BRASIL, 2017

Contudo, esta realidade não é exclusiva de grandes centros e regiões desenvolvidas. Segundo dados da Secretaria Municipal de Saúde (SESMA, 2016), 1.496 portadores do vírus faziam acompanhamento no Centro de Testagem e Aconselhamento (CTA) de uma cidade do Estado do Pará e registrou de janeiro de até o dia 28 de abril de 2016, 80 novos casos positivos de HIV/Aids nos 23 municípios da região atendidos pelo centro (BRASIL, 2016; ABARA WE et al, 2016). 
Nesse sentido, o trabalho em questão visa fazer relação entre os pacientes atendidos no CTA da cidade com as doenças oportunistas e que estão em tratamento. Analisando assim, o impacto que as doenças oportunistas têm sobre o prognóstico dos pacientes portadores do HIV. Logo, os resultados da presente pesquisa servirão para subsidiar discussões acerca da prevalência de infecções oportunistas em pacientes soropositivos para HIV, seus métodos diagnósticos e sintomas mais comuns, bem como fomentara divulgação dos serviços oferecidos pelo CTA do município e o enriquecimento da literatura sobre do tema.

Desta forma, a presente pesquisa teve como objetivos determinar a prevalencia de infecções oportunistas em soropositivos para o Vírus da Imunodeficiência Humana (HIV) atendidos no Centro de Testagem e Aconselhamento (CTA) de uma cidade do estado do Pará, no período de janeiro de 2015 a dezembro de 2016; Determinar o perfil epidemiológico dos pacientes HIV positivos no CTA do município; Verificar a existência de associação entre HIV positivo e sexo e Investigar a frequência de infecções oportunistas presentes nos portadores de HIV atendidos neste CTA.

\section{MÉTODOS}

Trata-se de um estudo descritivo, retrospectivo, observacional, transversal, que pretendeu determinar a prevalência de infecções oportunistas em pacientes HIV positivos na população de usuários do CTA, por meio de análise de prontuários médicos de todos os HIV positivos no período de janeiro de 2015 a dezembro de 2016. Portanto, não contempla intervenções que causassem quaisquer tipos de dor ou desconforto para os indivíduos incluídos no estudo e sem coleta de material biológico.

Os dados foram coletados dos prontuários dos pacientes e registrados em uma ficha elaborada pelos pesquisadores, cada ficha recebeu um código alfa numérico excluindo dessa forma a possibilidade de identificação do paciente.

Os dados necessários foram coletados de acordo com os preceitos da Declaração de Helsinque e do Código de Nuremberg, seguindo as determinações da Resolução 466/2012 do Conselho Nacional de Saúde. O presente estudo foi realizado com o aceite da gerência do CTA de uma cidade do Pará, aceite do orientador e a aprovação pelo Comitê de Ética em Pesquisa com Seres Humanos (CEP) sob número de parecer 2.545.567.

A pesquisa teve o cuidado de assegurar a confidencialidade dos dados, preservando, portanto, 0 anonimato e sigilo das informações coletadas. Os dados obtidos foram utilizados apenas para os objetivos deste projeto. Os pesquisadores se comprometeram em divulgar os resultados alcançados sem restrições.

Foram elegíveis para participar da pesquisa os pacientes HIV positivos de ambos os sexos, sem distinções de idade, atendidos no Centro de Testagem e Aconselhamento de Santarém, no período de janeiro de 2015 a dezembro de 2016.

O risco que essa pesquisa pôde enfrentar foi a falta de acesso aos arquivos do CTA e o inadequado preenchimento dos formulários médicos. Entretanto, com o intuito de reduzir esses riscos, os pesquisadores efetuaram visitas à instituição, em busca de apoio e avaliação da viabilidade da pesquisa e receberam todas as instruções necessárias da Diretoria do CTA. Além disso, é válido ressaltar que foram observadas as normas da Resolução 466/12 do CONEP, com o intuito de garantir o sigilo e a integridade dos pacientes.

\section{RESULTADOS E DISCUSSÃO}

No município de Santarém, de acordo com a pesquisa realizada no CTA foram atendidos, nos anos de 2015 e 2016, o total de 467 pacientes portadores de HIV. Ao determinar o perfil epidemiológico destes pacientes, verificou-se que $66 \%$, ou seja, 306, eram do sexo masculino e os demais $34 \%$ eram referentes ao sexo feminino, totalizando 161 pacientes. Logo, os dados demonstraram uma relação aproximada de dois homens afetados para cada mulher.

Verificou-se que no ano de 2015, 173 dos diagnósticos realizados eram de homens e 92 eram de mulheres. No ano de 2016, constatou-se que a quantidade de homens era maior que a de mulheres também, demonstrando que 133 eram homens e 69 pertenciam ao sexo feminino (Gráfico 1). 
Gráfico 1 - Relação de pacientes diagnosticados nos anos de 2015 e 2016 como sexo.

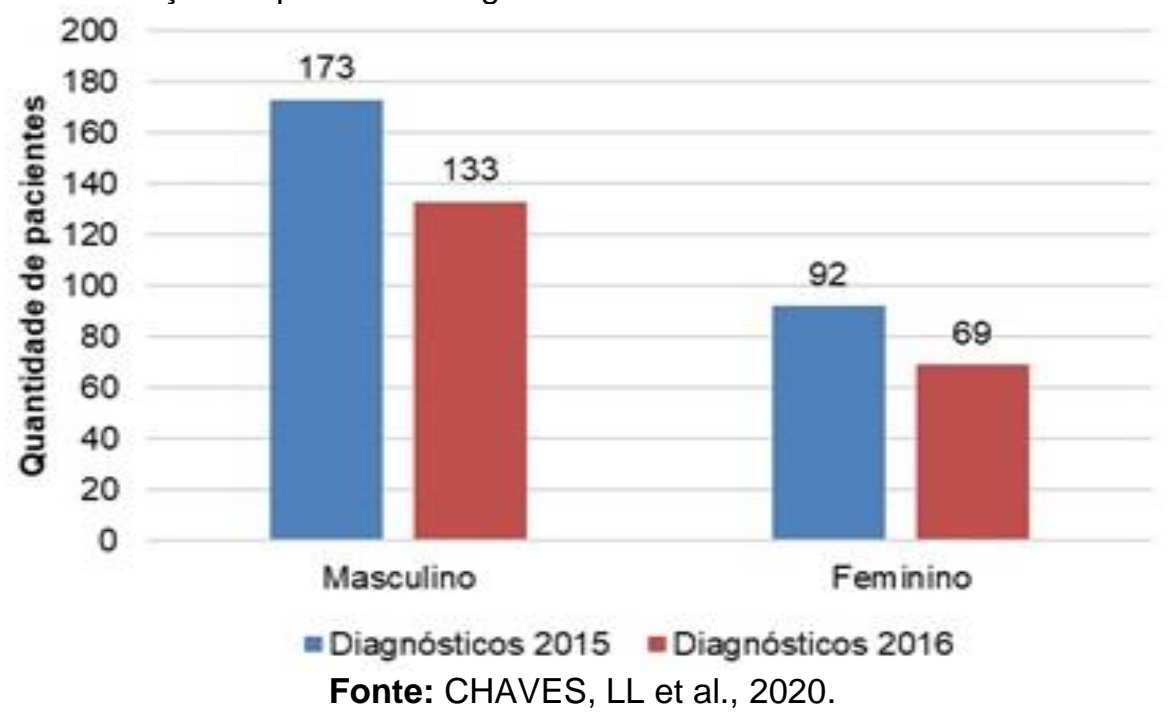

No Brasil, segundo o boletim epidemiológico, divulgado pelo Ministério da Saúde, de 1980 até junho de 2017, foram registrados $65,3 \%$ casos de aids em homens, totalizando 576.245 e 306.444 (34,7\%) em mulheres. A partir de 2009, observa-se uma diminuição gradual dos casos de aids em mulheres e um aumento nos casos em pacientes do sexo masculino, refletindo-se na razão de sexos, que passou a ser de 2,2 casos de AIDS em homens para cada mulher em 2016 (BRASIL, 2014; BRASIL, 2016).

Além disso, constatou-se que a quantidade de pacientes diagnosticados no ano de 2015 foi maior que no ano de 2016. Demonstrando uma diferença de 63 pacientes de um ano para o outro. Segundo o Boletim epidemiológico, a taxa de detecção de AIDS vem caindo gradativamente no Brasil nos últimos anos. De 2012 para 2013, a taxa caiu 1,4\%; de 2013 para 2014, a redução foi de 3,6\%; de 2014 para 2015, de 4,2\%; e de 2015 para 2016, de 5,2\%. Em um período de dez anos, apresentou queda de 5,1\%: em 2006 a taxa foi de 19,9 casos/100 mil habitantes e, em 2016, de 18,5/100 mil habitantes (BRASIL, 2016).

Esse contexto faz um contraponto com os altos índices de pessoas com o HIV na década de 80, haja vista atualmente, ocorrer mais subnotificação do que no passado e enraização do preconceito contra esta doença na sociedade, permitindo que muitas pessoas não sejam diagnosticadas como deveriam (BRASIL, 2016).

Foi analisado os motivos para o aumento da taxa de infecção e resultados positivos com o passar dos anos e foram encontradas explicações tais como no passado não existia maiores quantidades de testes que permitissem a quantificação real de pessoas com o vírus, além disso, é também avaliado que atualmente existe maior divulgação sobre a doença e o teste rápidos em meios de comunicação como TV e Internet, permitindo com que diminuísse a estigmatização do HIV ser uma doença exclusiva de um grupo social (como taxado na década de 1980 para homossexuais), além disso há hipótese de que, pelo avanço da medicina na construção de medicamentos que controlasse a doença e melhorasse a imunidade, as pessoas, principalmente com baixa escolaridade, assumem que não há problemas adquirir esta doença pois as medicações a controlam com qualidade, diminuindo a prevenção e se expondo cada vez mais ao risco de se infectar (BRASIL, 2016).

Em vários estudos, este fato é corroborado haja vista os homens terem maior taxa de prevalência de infecção devido a fatores tais como o machismo que impera na sociedade gerando a ideia de que o homem não deve usar preservativo por diminuição do prazer ou que por este fato seria motivo de exclusão social na comunidade de amigos levando a exposição e ao risco maior de contágio com a doença, sem contar o fato de que historicamente os homens possuem menos vontade de testagem rápida e menos idas ao médico para uma avaliação médica e isso encontra fundamento e explicação com base no machismo estrutural e perpetuação da ideia social de que a mulher que se cuida mais e por isso, este fato não deve ser alterado. (TREVISOL FS, et al, 2010; ABARA WE, et al, 2016). 
Ao determinar a faixa etária dos pacientes diagnosticados, é cabível afirmar que, o período entre os 21 e 30 anos de idade é o que ocorreu a maioria das detecções, somando cerca de 37\%, ou seja, 162 do total de 467 dos pacientes atendidos nos dois anos. Em seguida, a faixa entre os 31 e 40 anos é a com maior prevalência, totalizando 123 casos. A faixa etária que registrou a menor quantidade de pacientes foi a entre 71 e 80 anos (Gráfico 2).

Gráfico 2 - Quantidade de pacientes de acordo com a faixa etária.

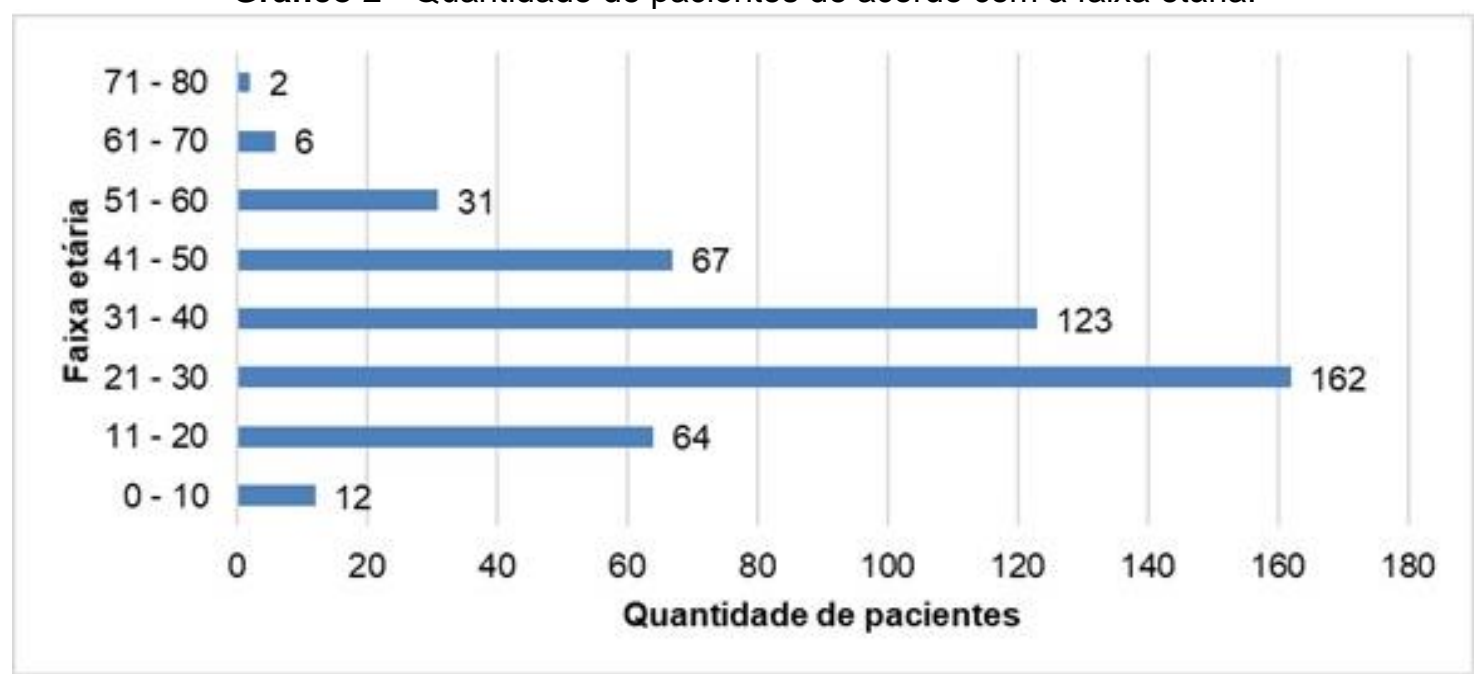

Fonte: CHAVES, LL et al., 2020.

Este estudo encontrou informações que discordam de pesquisas de outras cidades. Quanto à análise da idade com a infecção do HIV, outras pesquisas encontraram que a faixa etária com mais casos estava entre 41-50 anos de idade e buscou relação com análise de terem se infectado primeiro, permitindo inferir a maior idade e a necessidade do uso de tratamento farmacológico (TREVISOL FS, et al., 2010; BALDAN SS, et al., 2017).

Discordante disso, a atual pesquisa encontrou a faixa etária mais prevalente entre 21-30 anos (162 casos) e 31-40 (123 casos), o que permite inferir que quem mais está se infectando são jovens que não viveram e, por isso, não se lembram da epidemia do HIV da década de 80 , encontrando-se em uma sociedade que já avançou quanto a tratamento e controle da doença e sua carga viral, permitindo com que parte da população, associando a outros fatores como baixa escolaridade, analise que a infecção pelo vírus não é danosa ao ser humano por ter medicamentos pra controle, diminuindo então as medidas de prevenção e se expondo mais ao risco de se infectar pelo vírus (BALDAN SS, et al., 2017).

Ao questionar sobre a orientação sexual dos pacientes entrevistados, constatou-se que mais de $60 \%$ (185) dos homens portadores de HIV declaram-se heterossexuais, enquanto $100 \%$ das mulheres atendidas consideram-se heterossexuais, totalizando 161 pacientes do sexo feminino. Além disso, 100 dos 306 homens entrevistados, afirmam que são homossexuais por orientação sexual e 21 deles declaram-se bissexuais (Gráfico 3).

De acordo com o Ministério da Saúde, entre os homens, destaca-se o aumento em jovens de 15 a 19 anos e de 20 a 24 anos: do ano de 2006 para o de 2016, a taxa quase triplicou entre o primeiro grupo e, entre os de 20 a 24 anos, a taxa mais que duplicou. Mesmo com esses aumentos observados, a maior taxa de detecção em 2016 permaneceu entre os indivíduos na faixa etária de 35 a 39 anos: 49,4 casos/100.000 habitantes, 21,5\% menor do que a observada em 2006 (BRASIL, 2016).

No entanto, entre as mulheres, verifica-se que nos últimos dez anos a taxa de detecção vem apresentando uma tendência de queda em quase todas as faixas etárias, exceto entre as de 15 a 19 e 60 anos e mais: nestas, foram observados aumentos de 13,9\% entre as mais jovens e de $14,3 \%$ entre as de maior faixa de idade, quando comparados os anos de 2006 e 2016 (BRASIL, 2017). 


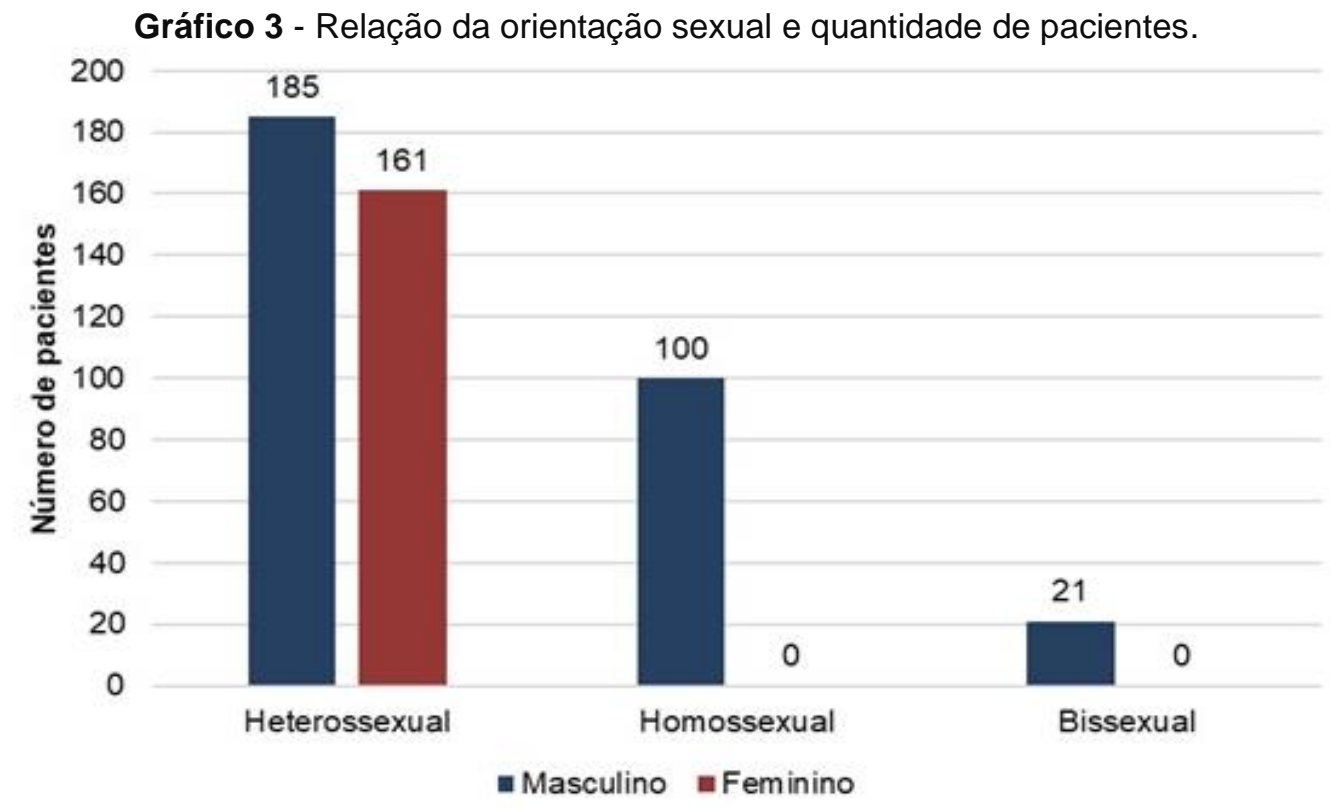

Fonte: CHAVES, LL et al., 2020.

A relação de orientação sexual influenciar no contato com a doença é uma associação arcaica. Em outros estudos de perfil epidemiológico, a avaliação da homossexualidade não possui relação com adquirir o vírus HIV, sendo que a doença é encontrada em mais pessoas heterossexuais quando estudado em formato de pesquisa retrospectiva. (TREVISOL FS, et al, 2010; ARAUJO TM, et al, 2012). Esse fato deve ser levado em consideração para diminuir o preconceito ainda existente na sociedade que perdura desde 1980 com a epidemia do HIV nos Estados Unidos da América (EUA), onde era avaliado que quem adquiria o vírus eram homossexuais, sendo que esta suposição ainda deve ser combatida (BRASIL, 2017).

Analisando este fato, há maior número de casos na cidade do CTA por diversas hipóteses tais como as pessoas de fora da cidade não irem ao CTA para testar a doença pela distância entre cidades, além disso ocorre subnotificação nas outras cidades pois não há quantidade suficientes de testes enviados para as atenções básicas das outras cidade (CUNHA CB, 2015). Quanto à escolaridade, 211 dos pacientes entrevistados afirmaram ter o Ensino Fundamental completo, 181 disseram possuir Ensino Médio completo e apenas 59 pacientes, ou seja, cerca de 13\% possuíam Ensino Superior completo. Além disso, 12 dos participantes eram analfabetos (Gráfico 4).

Gráfico 4 - Relação da escolaridade e a quantidade de pacientes.

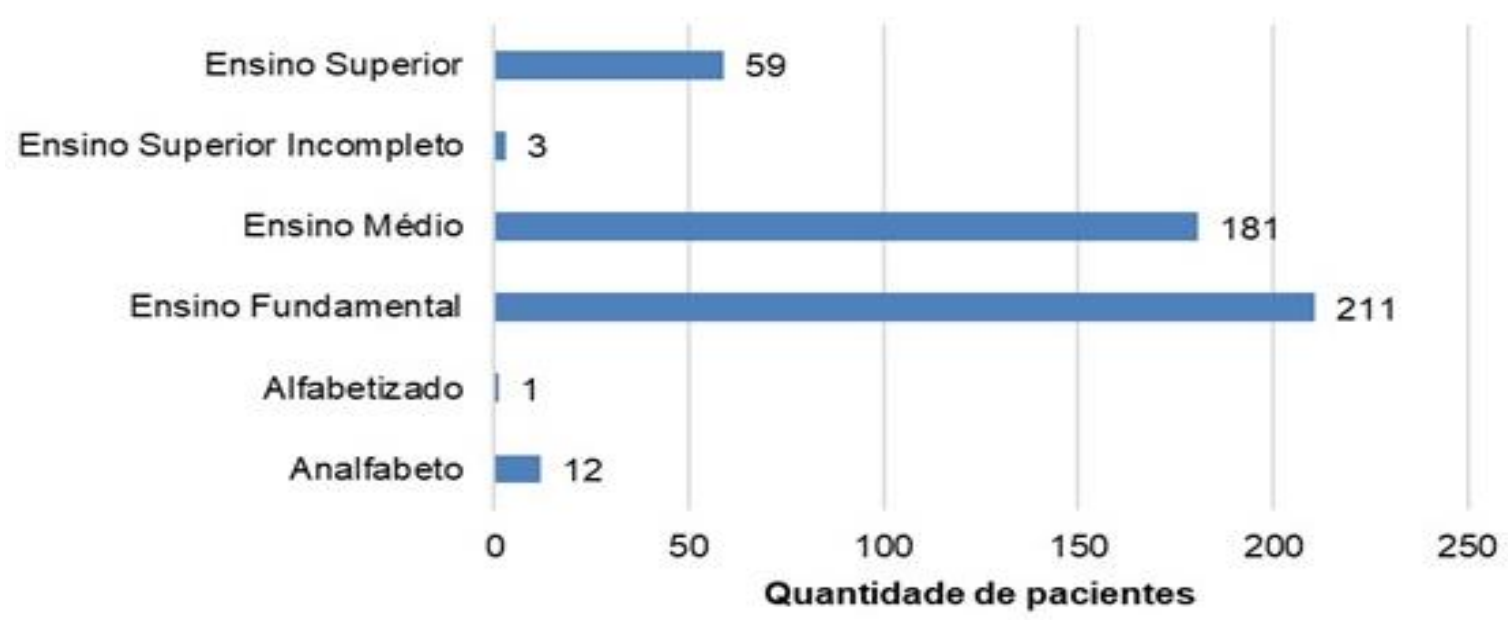

Fonte: CHAVES, LL et al., 2020. 
Em outra pesquisa, realizada em Santa Catarina, estado Brasileiro, foi encontrado semelhança pois a maioria das pessoas com HIV tinham menos de 8 (oito) anos de estudo, classificando-se em analfabeto, alfabetizado e ensino fundamental, sendo este fato associado com situação socioeconômica e isto influenciar no aumento do número de casos.

Em outro estudo, foi encontrada associação da diminuição do número de casos nas pessoas com mais anos de estudo o que concorda com a pauperização da epidemia no país, haja vista avaliar-se que quando menos anos escolares menos conhecimento de prevenção ou esclarecimento de combate à doença. (GABRIEL R, et al., 2005; TREVISOL FS, et al., 2010; BRASIL, 2010)

Dentre os pacientes entrevistados, buscou-se analisar a quantidade de infectados pelo HIV que apresentaram doenças oportunistas. Com a pesquisa, verificou-se que a enfermidade que mais atingiu os positivados foi a tuberculose, constatou-se com a análise que houve 35 casos de tuberculose registrados em pacientes portadores do vírus em questão.

Em seguida, a neurotoxoplasmose registrou 15 casos de pacientes afetados. Houve 10 casos de candidíase oral, ou monilíase, que é uma infecção causada pelo excesso de fungo Candida albicans na boca, que causa infecção, geralmenteembebês, devido a sua imunidade ainda pouco desenvolvida, ou em adultos com o sistema imune enfraquecido devido a gripes, doenças crônicas ou HIV, por exemplo.

A herpes Zoster, que é uma infecção viral capaz de provocar bolhas na pele e dor intensa, pode acometer qualquer região, mas é mais comum no tronco e no rosto. As lesões, geralmente, se manifestam na forma de uma faixa em um dos lados do corpo, registrou 5 casos e foram notificados 3 pacientes portadores de HIV atendidos no CTA com neurotuberculose nos anos de 2015 e 2016. Outras doenças oportunistas como pneumocistose e toxoplasmose apresentaram 2 casos. Além dessas doenças como Paracoccidioidomicose, hepatite A, criptoccocose, neurosífilis, neuropatia periférica e neurocripto, tiveram 1 caso, cada, notificados em pacientes atendidos no CTA (Gráfico 5).

Gráfico 5. Relação de pacientes positivos para o HIV com doenças oportunistas.

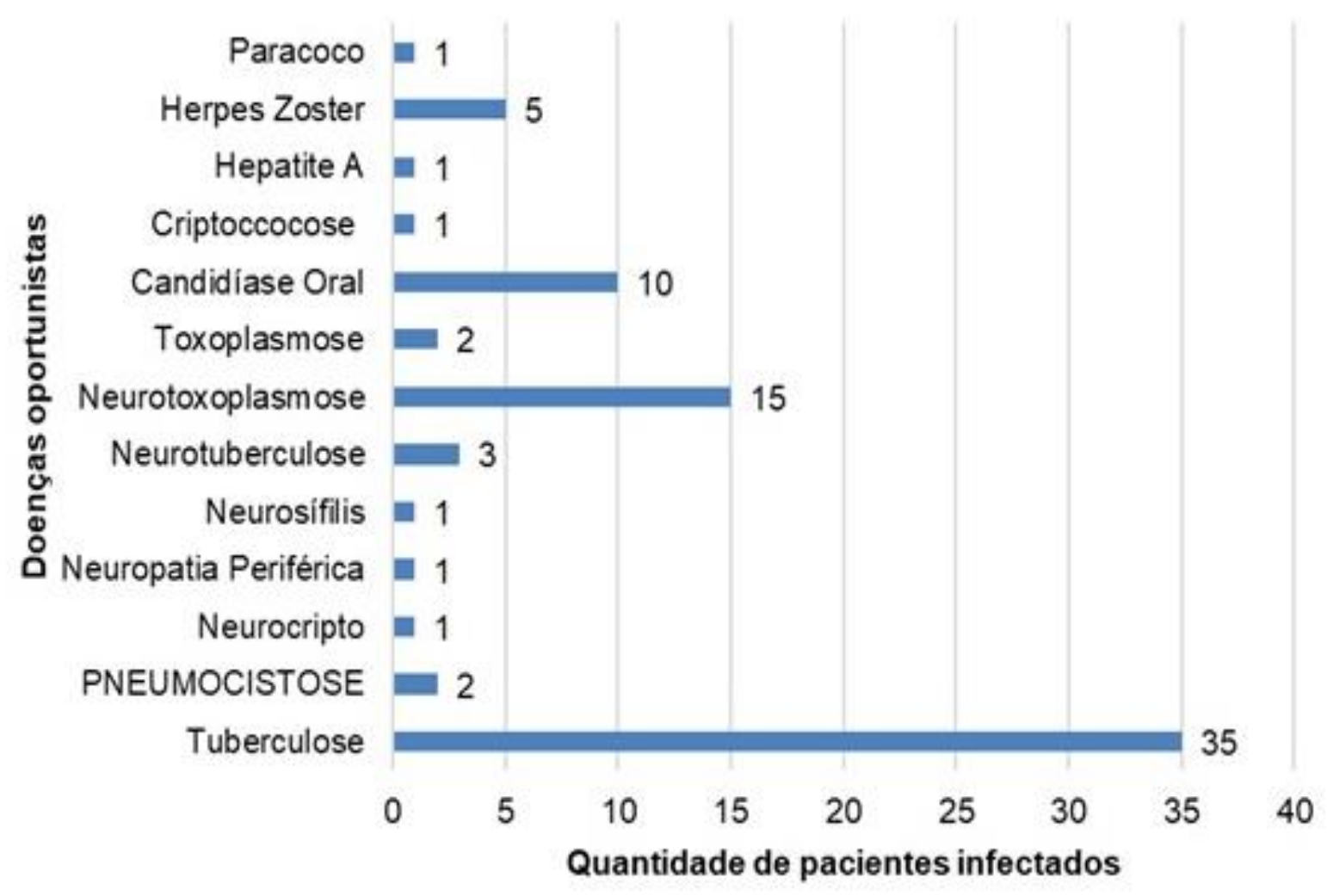

Fonte: CHAVES, LL et al., 2020. 
Quanto à avaliação de doenças oportunistas com a infecção pelo HIV, em outra pesquisa, realizada na cidade de São Paulo, foi encontrado que a maioria possui Tuberculose, Pneumocistose e Toxoplasmose, discordando com a atual pesquisa que encontrou que a maioria possui Tuberculose (35 casos) e Neurotoxoplasmose (15 casos) (GABRIEL R, et al., 2005; WANG H, et a., 2016). É analisado que há associação, por diversos fatores, da interrupção ou erro na tomada da medicação que controla a carga viral (CV) e, com esta taxa aumentando, ocorre diminuição do vigor da imunidade, aumentando o risco de infecção do paciente com HIV por outras doenças. Além disso, é analisado, na maioria das pesquisas, que a doença oportunista que mais infecta o paciente com CV alto é a tuberculose, contudo há variações regionais que permitem a infecção de doenças variadas de acordo com a cidade, estado ou região como comparado nesta pesquisa (WANG H, et al., 2016).

Dessa forma, é importante analisar que os resultados da pesquisa são semelhantes a maioria dos cenários nacionais por se tratar de infecção associada com Tuberculose e Neurotoxoplasmose e essa realidade possui prejuízos para o paciente, pois são doenças com alto risco de letalidade caso não controlado a taxa de vírus do HIV e não tratado a doença associada, podendo levar ao óbito e até infecção de outras pessoas (WANG H, et al., 2016).

Na pesquisa, constatou-se também que 83 dos 467 pacientes analisados, possuíam, coinfecção do HIV com Sífilis, ou seja, cerca de $18 \%$ dos pacientes. Em seguida, o Papiloma Vírus Humano (HPV), apresentando 15 casos de coinfecção, a Gonorreia posiciona se em 7 casos registrados. Tanto a Herpes simples, quanto a Hepatite B apresentaram 4 casos notificados e a Herpes genital, a Hepatite C e o Condiloma, notificados 2 casos cada de coinfecção com o HIV e o Cranco, juntamente com a Clamídia demostraram 1 caso cada de infecção em pacientes portadores do vírus HIV.

Esse contexto de outras infecções é uma realidade variada de região para região, contudo é importante destacar que algumas doenças tais como Sífilis, HPV, Gonorreia e a Clamídia não possuem uma alta letalidade, contudo possuem importância no quesito de uma mulher gestante que tem a possibilidade de passar para o recém nascido por meio vertical (durante a gestação) ou do homem que possui essas infecções e passa para a gestante por meio de relação sexual que então transmite ao seu feto, podendo gerar consequências danosas ao recém nascido tais como baixo peso ao nascer, prematuridade, cegueira e até óbito fetal (BRASIL, 2010).

Diversas limitações e dificuldades de realização do estudo foram encontradas, bem como em outras pesquisas de âmbito nacional, tais como falta de preenchimento de fichas de notificação compulsória ou não preenchimento da total de prontuários médicos, dificultando a construção de um bando de dados completamente fidedigno à realidade da localidade (TREVISOL FS, et al, 2010; BRASIL, 2015). Contudo, este estudo permitiu a comparação da realidade do estabelecimento com o levantamento epidemiológico de outras regiões do país no que tange o perfil da infecção pelo HIV e AIDS, podendo contribuir para desenvolvimento de medidas preventivas focadas na população que mais se infecta, diminuindo custos operacionais e aumentando a eficácia de educação em saúde.

\section{CONCLUSÃO}

Por meio desta pesquisa foi encontrado que a maioria dos casos de HIV no CTA escolhido são homens, de idade entre 21 e 40 anos, heterossexuais, com escolaridade de ensino fundamental ou médio, oriundos da cidade que está localizado o CTA, possuindo coinfecção com a Sífilis e os que possuem CV alta, por algum motivo, se infecta com Tuberculose ou Neurotoxoplasmose. Além disso, diagnóstico da AIDS está relacionado à presença de infecções consideradas oportunistas que tendem a se manifestar em indivíduos imunossuprimidos como foi encontrado pela pesquisa. Por meio desta pesquisa foi possível encontrar o perfil epidemiológico dos pacientes com HIV atendidos no local sendo uma pesquisa que servirá para o desenvolvimento de busca ativa por meio dos órgãos de saúde e educação em saúde direcionada. Concluise que ainda existe uma alta taxa destas infecções entre esses pacientes e que eles muitas vezes possuem importantes comorbidades associadas que agravam o quadro clínico e prognóstico. Por isso, trabalhos com essa finalidade são de fundamental importância para a população e profissionais de saúde. 


\section{REFERÊNCIAS}

1. ABARA WE, et al. Syphilis trends among men who have sex with men in the United States and Western Europe: a systematic review of trend studies published between 2004 and 2015. PLoS One. 2016

2. ARAÚJO TM, et al. Neurotoxoplasmose em pacientes com hiv/aids internados em unidade de terapia intensiva. Revista de enfermagem UFPE on line, 2012; 6(5): 1046-52.

3. BALDAN SS, et al. Características clínico-epidemiológicas da coinfecção por tuberculose e HIV e sua relação com o Índice de Desenvolvimento Humano no estado do Mato Grosso do Sul, Brasil. Rev Pan-Amaz Saude 2017; 8(3): 5967.

4. BRASIL. Ministério da Saúde, Secretaria de Vigilância em Saúde. Departamento de DST Aids e Hepatites Virais. Protocolo Clínico e Diretrizes Terapêuticas para Prevenção da Transmissão Vertical de HIV, Sífilis e Hepatites. 1a edição. Brasília: Ministério da Saúde; 2015. http://www.aids.gov.br/pcdt.

5. BRASIL. Ministério da Saúde. Secretaria de Vigilância em Saúde. Departamento de Vigilância das Doenças Transmissíveis. Manual dos Centros de Referência para Imunobiológicos Especiais. 4. ed. Brasília: Ministério da Saúde; 2014.

6. BRASIL. Ministério da Saúde, Secretaria de Vigilância em Saúde, Departamento de Vigilância das Doenças Transmissíveis. Plano nacional pelo fim da tuberculose [Internet]. Brasília: Ministério da Saúde; 2017.

7. BRASIL. Ministério da Saúde, Secretaria de Vigilância em Saúde, Departamento de Vigilância, Prevenção e Controle das Infecções Sexualmente Transmissíveis, do HIV/Aids e das Hepatites Virais. Protocolo clínico e diretrizes terapêuticas para manejo da infecção pelo HIV em adultos. Brasília: Ministério da Saúde; 2018

8. BRASIL. Ministério da Saúde. Secretaria de Vigilância em Saúde. Perspectivas brasileiras para o fim da tuberculose como problema de saúde pública. Bol Epidemiol. 2016;47(13):1-15.

9. BRASIL. Ministério da Saúde. Departamento de AIDS, DST e Hepatites virais. Hepatites Virais. Bol. Epidemiol. 2010; $3(1): 1-62$

10. BRITO AM, et al. AIDS e infecção pelo HIV no Brasil: uma epidemia multifacetada. 2000.

11. CUNHA CB, et al. Chlamydia trachomatis, neisseria gonorrhoeae and syphilis among men who have sex with men in Brazil. BMC Public Health. 2015.

12. GABRIEL R, et al. Perfil epidemiológico dos clientes com HIV/AIDS na unidade ambulatorial de hospital escola de grande porte - município de São Paulo. Rev Latino-am Enfermagem 2005; 13(4):509-13

13. LIMA LB. Transmissão vertical do HIV e suas medidas de prevenção no hospital universitário-UFSC. 2011.

14. MAGNO ES, et al. Fatores associados à coinfecção tuberculose e HIV: o que apontam os dados de notificação do Estado do Amazonas, Brasil, 2001-2012. Cad. Saúde Pública 2017; 33(5):e00019315

15. MAHY M, et al. Measuring the impact of the global response to the AIDS epidemic: challengesand future directions. Journal of Acquired Immune Deficiency Syndromes. 2009; 52 Suppl 2:S152-159.

16. TREVISOL FS, et al. Perfil epidemiológico dos pacientes com HIV atendidos no Sul de Santa Catarina, Brasil, 2010. Epidemiol. Serv. Saúde, Brasília, 2013; 22(1):87-94.

17. WANG H, et al. Estimates of global, regional, and national incidence, prevalence, and mortality of HIV, 1980-2015: the Global Burden of Disease Study 2015. Lancet HIV. 2016. 